\title{
Bioanalysis
}

\section{Bioanalytical methods for food allergy diagnosis, allergen detection and new allergen discovery}

For effective monitoring and prevention of the food allergy, one of the emerging health problems nowadays, existing diagnostic procedures and allergen detection techniques are constantly improved. Meanwhile, new methods are also developed, and more and more putative allergens are discovered. This review describes traditional methods and summarizes recent advances in the fast evolving field of the in vitro food allergy diagnosis, allergen detection in food products and discovery of the new allergenic molecules. A special attention is paid to the new diagnostic methods under laboratory development like various immuno- and aptamer-based assays, including immunoaffinity capillary electrophoresis. The latter technique shows the importance of MS application not only for the allergen detection but also for the allergy diagnosis.

\section{Allergy \& allergens: general information}

Allergy is defined as an abnormal immunological response of the humane body to an otherwise innocuous antigen [1]. It is estimated to affect around $20 \%$ of the world population, mainly in the industrialized countries. In particular, food allergies are common among $2 \%$ of the adult population and especially acute in the childhood, affecting $6-8 \%$ of children and infants [2]. The specific characteristics of the allergy as an immunological disorder, also called type I hypersensitivity, are different hypersensitivity reactions, mediated by the IgE antibodies production in human body exposed to the harmful antigens, in other words, allergens [1]. The presence of $\operatorname{IgE}$ antibodies in the mechanism of the allergy development differs it from food intolerance, which is either the result of immune non- $\operatorname{IgE}$ mediated reactions or nonimmune responses of the human body to the consumption of food products or medication [3].

During the normal immunological response, the antigen (potential allergen) triggers in the human organism the production of IgG1 and IgG4 antibodies at low levels by the B-cells, which were activated via cytokines released from type $1 \mathrm{~T}$ helper cells (TH1) [4]. The first abnormal contact of the immune system with an antigen (future allergen), which is often present at a low dose and penetrates into the organism transmucosally, leads to the activation of $\mathrm{TH} 2$ cells instead of TH1 cells, as schematically illustrated in Figure 1 (upper panel). As a consequence, the TH2 cells release a cytokine IL- 4 that triggers the switching of the B-cells to the production of the antigen-specific IgE antibodies instead of $\operatorname{IgG}$ isotypes. In contrast with other antibody isotypes, $\operatorname{IgE}$ antibodies are located predominantly in tissues being tightly bound to the mast-cell surfaces through the high affinity IgE receptor, known as FceRI. Therefore, when an allergen enters into the organism for the second time, it binds to IgE antibodies via epitope recognition, leadings to the cross-linking of FceRI receptors followed by the mast-cell activation. Activated mast-cells degranulate and release various chemical mediators, which start the cascade of the events resulting in the development of a type I hypersensitivity, in other words, allergic reactions. Basophils and activated eosinophils also express FceRI receptors and can also participate in the allergy development [1,5].
Natalia Gasilova' \& Hubert $\mathrm{H}$ Girault ${ }^{*, 1}$

'Laboratoire d'Electrochimie Physique et Analytique, Ecole Polytechnique Fédérale de Lausanne, Station 6, CH-1015 Lausanne, Switzerland

*Author for correspondence:

Tel.: +410216933151

Fax: +410216933667

hubert.girault@epfl.ch 


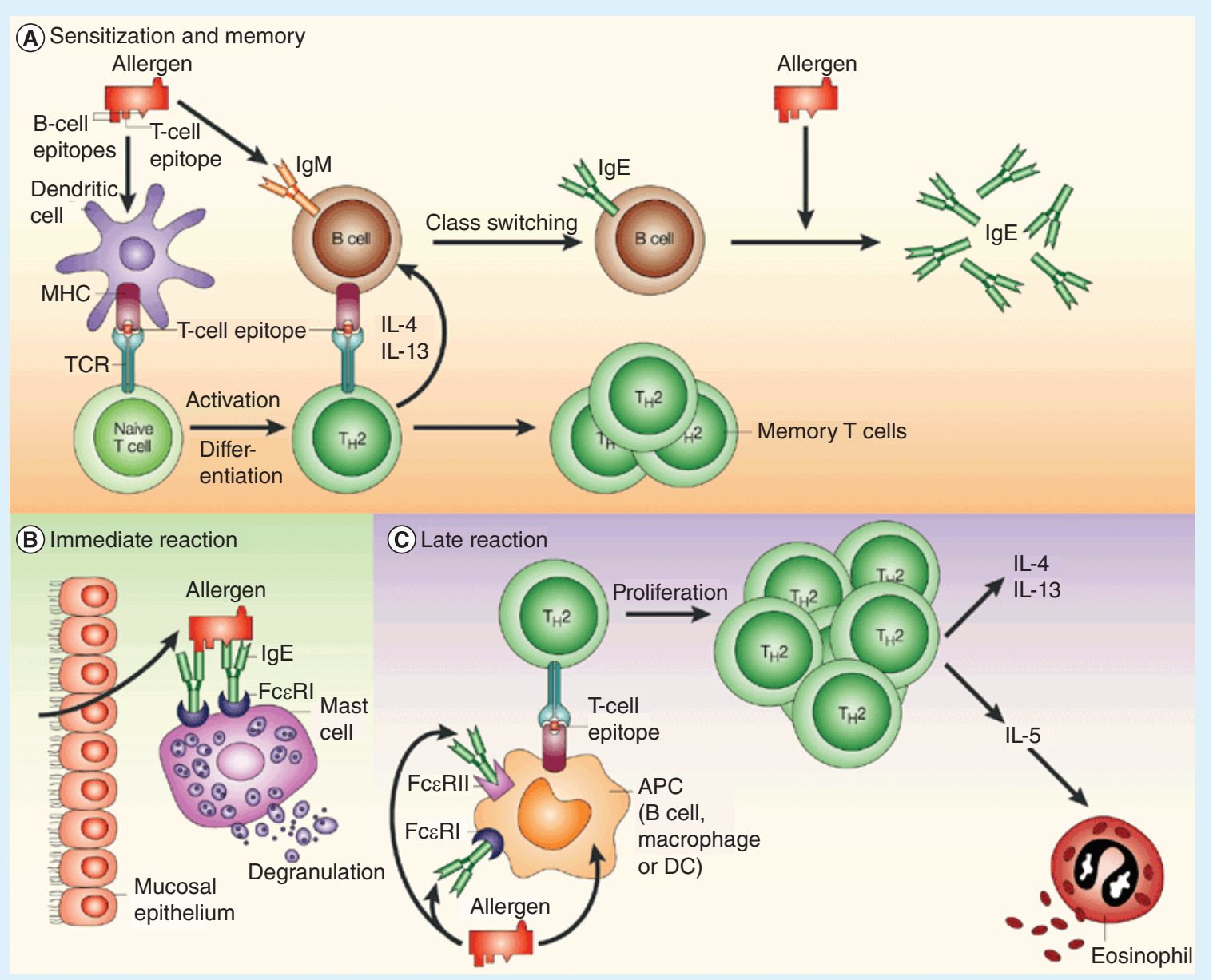

Figure 1. Representation of the allergy development. (A) First sensitization by the allergen and memory effect; (B) immediate organism reaction leading to the degranulation of the mast cells; (C) late phase reaction involving eosinophil activation.

Reproduced with permission from [5] @ Nature Publishing Group Ltd. (2002).

The mediators released during the degranulation of activated mast-cells are, for example, histamine, $\mathrm{N}$-acetylhexosaminidase, proteases, leukotrienes or proinflammatory cytokines. These compounds are responsible for the development of different allergic reactions, such as allergic rhinitis, asthma, systemic anaphylaxis and acute urticarial syndrome.

The types of IgE-mediated responses vary with the individual properties of the organism, the path of allergen penetration (inhalation, injection, oral or subcutaneous administration) and allergen dosage [1]. In the case of food allergy, the most common allergic reactions are vomiting, diarrhea, pruritis and urticaria.

As all known allergenic compounds, food allergens are proteins or glycoproteins, often possessing enzymatic activity, which increases their mucosal permeability [1]. They represent one of the biggest group of sensitizers with over 180 identified allergenic molecules [2]. The most common allergen sources including milk, eggs, peanuts, soybeans, seafood, fish, wheat and tree nuts are referred to as the "Big Eight" of food allergens [6]. Despite the origin from different sources, some of the allergenic molecules share similar structural patterns and, therefore, their recognition by $\operatorname{IgE}$ antibodies is realized via the same epitopes. If the structural similarity between allergens is greater than $70 \%$, it causes so-called cross-reactivity allergic syndrome, for example, latex-fruit syndrome, consisting of the patient sensitization to the allergens from both sources, latex and fruits, simultaneously [7]. Cross-reactivity typically happens between homologous proteins from the specific family of molecules, for example, between milk proteins from different mammals. However, it is observed also between proteins from phylogenetically different sources because of the evolutionary highly conserved structure of these molecules like, for instance, sugar moieties in food and plant pollen $[7,8]$. 
As was already mentioned above, allergy symptoms vary from mild ones, like allergic rhinitis, to severe and life-threatening ones, like anaphylaxis, making this disease one of the emerging problems of the modern society [2]. The prevalence of allergic diseases such as allergic rhinitis, asthma and atopic eczema, in last few decades was related at the beginning with the socalled "hygienic hypothesis." This hypothesis explains the proliferation of type I hypersensitivity in Western countries with the absence of bacterial and viral crossinfection opportunities in the families due to their size reduction and improved personal hygiene [9]. However, recent studies have shown that the diet and bacterial metabolites produced by commensal microbiota play a more important role in the status and functioning of the immune system [10,11]. The insufficient exposure to dietary and bacterial metabolites because of the "Western-lifestyle," typically associated with the low fiber consumption (including vegetables and fruits) together with high fat intake, leads to the immunological disorders, represented not only by the allergies, but also by diabetes and autoimmune diseases [12]. Therefore, the consumption of healthy food products together with the manipulation of the gut microbiota using probiotics could potentially help to decrease and prevent the development of various inflammatory disorders, including allergies.

\section{Allergy diagnosis}

Reliable and efficient methods of allergy diagnosis are very important for its proper treatment and prevention. Two main types of allergy diagnosis used nowadays, consist of in vivo and in vitro tests, which should be performed in parallel for the more precise diagnostics [13].

\section{In vivo allergy diagnosis}

The recommended in vivo tests are skin prick test (SPT), oral food challenge and suspicious product elimination diet, applicable in case of food allergies [14]. Oral food challenge is the controlled administration of allergens to the patient and is regarded as a "golden standard" for the allergy diagnosis [15]. However, it is a risky procedure due to the potential development of anaphylaxis or other adverse reactions by the patient. Therefore, SPTs, which are realized via pricking the patient skin with the needle containing small amount of the allergen, are regarded as a safer way of allergy diagnosis, but unfortunately less reliable [13,14].

\section{In vitro allergy diagnosis}

All in vitro allergy tests can be divided into two groups: $\mathrm{IgE}$ quantification-based and $\mathrm{IgE}$ quantification-free diagnostic procedures. These currently existing methods (commercialized and under laboratory development) are summarized in the Table 1.

\section{IgE quantification-free tests}

Among the IgE quantification-free techniques, in vitro basophil activation test becomes more and more popular for the allergy diagnosis [16]. This method consists of the flow cytometry of the patient basophils, activated by the binding of the allergen extract or recombinant allergens to IgE antibodies present on the basophil surface [17]. Such type of in vitro testes provides reliable results, complementary to $\mathrm{IgE}$ quantificationbased methods, and is also useful in case of non- $\operatorname{IgE}$ mediated hypersensitivity reactions $[18,19]$. Commercial ready-to-use kits for the performance of basophil activation test are available on the market [20]. Another IgE quantification-free way of the allergy diagnosis, which was reported recently, is based on the quantification of allergen-specific TH2 cells in the blood serum [21].

\section{IgE quantification-based tests}

In clinical practice, the most popular in vitro ways of the allergy diagnosis belong to the group of IgE quantification-based techniques: they are based on the quantification of total or specific $\operatorname{IgE}$ antibodies, as these immunoglobulins are universal biomarkers of the allergic sensitization. For a nonallergic person, the total level of $\operatorname{IgE}$ antibodies varies significantly during the lifetime: from the birth to the age of $15-20$, it increases steadily from less than $2.4 \mathrm{ng} / \mathrm{ml}(<1 \mathrm{IU} / \mathrm{ml})$

\section{Key terms}

B-cells: Type of lymphocytes that mature in the bone marrow and are responsible for the antibodies production in the humoral adaptive immunity.

T helper cells: Type of lymphocytes that mature in human thymus, play a major role in the adaptive immune system by regulating immune responses via activation of other immune cells, like B-cells.

Mast-cells: Type of granulocytes derived from myeloid stem cells, that are located in the tissues, play key role in the inflammatory processes (especially allergies), wound healing and defense against pathogens.

Basophils: Type of white blood cells, granulocytes, that circulate in the blood stream and are involved in inflammatory processes, allergies and defense against parasite infections.

Eosinophils: Type of white blood cells, granulocytes, that migrate in the blood stream, are involved in the allergy mechanisms and responsible for fitting multicellular parasites and certain infections.

Flow cytometry: Laser-based biophysical technology, employed mainly for cell counting and sorting by the introduction of cells in a fluid stream with electronic detection apparatus. 
Table 1. Current in vitro techniques for allergy diagnosis.

\begin{tabular}{|c|c|c|c|c|c|c|}
\hline & Technique & $\operatorname{LOD}(\mathrm{ng} / \mathrm{ml})^{\ddagger}$ & Sample volume $(\mu \mathrm{l})$ & Sample type & Analysis time & Ref. \\
\hline \multirow[t]{3}{*}{ Commercial } & $\begin{array}{l}\text { Basophil activation } \\
\text { test }^{\dagger}\end{array}$ & $\begin{array}{l}<5 \% \text { of } \\
\text { activated } \\
\text { basophils }\end{array}$ & 50 & Whole blood & $1 \mathrm{~h}$ & {$[20]$} \\
\hline & Classical ELISA & 12 & 20 & Blood serum & $2 \mathrm{~h}$ & {$[23]$} \\
\hline & Microarray chip (ISAC) & 0.24 & 30 & $\begin{array}{l}\text { Blood plasma/ } \\
\text { serum }\end{array}$ & $\leq 4 \mathrm{~h}$ & {$[24]$} \\
\hline \multirow[t]{11}{*}{$\begin{array}{l}\text { Under laboratory } \\
\text { development }\end{array}$} & $\begin{array}{l}\text { Microarray chip with } \\
\text { DLC solid support }\end{array}$ & $0.03-0.06$ & $1-2$ & $\begin{array}{l}\text { Blood serum/ } \\
\text { saliva }\end{array}$ & $\leq 4 \mathrm{~h}$ & {$[25]$} \\
\hline & $\begin{array}{l}\text { Nanoparticle- } \\
\text { enhanced SPR }\end{array}$ & 0.00018 & $<20$ & $\begin{array}{l}\text { Standard IgE } \\
\text { solution }\end{array}$ & $\leq 2 \mathrm{~h}$ & {$[26]$} \\
\hline & $\begin{array}{l}\text { Nanocrystal } \\
\text { clusters-enhanced } \\
\text { immunoassay }\end{array}$ & 0.005 & 100 & $\begin{array}{l}\text { Standard IgE } \\
\text { solution }\end{array}$ & overnight & {$[27]$} \\
\hline & $\begin{array}{l}\text { Nanoparticle hybrid } \\
\text { probe-enhanced } \\
\text { immunoassay }\end{array}$ & 0.04 & 30 & $\begin{array}{l}\text { Standard IgE } \\
\text { solution }\end{array}$ & $2 \mathrm{~h}$ & {$[28]$} \\
\hline & $\begin{array}{l}\text { Electrochemical } \\
\text { immunosensor }\end{array}$ & 0.24 & 100 & Blood serum & $2 \mathrm{~h}$ & [29] \\
\hline & $\begin{array}{l}\text { Magnetophoretic } \\
\text { immunoassay }\end{array}$ & $0.056-0.09$ & 10 & Blood serum & $\leq 30 \mathrm{~min}$ & {$[30]$} \\
\hline & $\begin{array}{l}\text { Aptamer-barcode } \\
\text { enhanced } \\
\text { chemiluminescence } \\
\text { immunosensor }\end{array}$ & 0.87 & 50 & Blood serum & $2.5 \mathrm{~h}$ & {$[31]$} \\
\hline & $\begin{array}{l}\text { Aptamer affinity } \\
\text { probe capillary } \\
\text { electrophoresis }\end{array}$ & 7 & 30 & Blood serum & $1 \mathrm{~h}$ & {$[32]$} \\
\hline & $\begin{array}{l}\text { Electrochemical } \\
\text { aptasensor }\end{array}$ & 1.1 & n.i. & $\begin{array}{l}\text { Standard IgE } \\
\text { solution }\end{array}$ & $1.5 \mathrm{~h}$ & [33] \\
\hline & $\begin{array}{l}\text { Lateral flow } \\
\text { microarrays }\end{array}$ & 2.4 & 30 & Blood serum & $\leq 10 \mathrm{~min}$ & {$[34]$} \\
\hline & $\begin{array}{l}\text { Immunoaffinity } \\
\text { capillary } \\
\text { electrophoresis }\end{array}$ & $0.24-2.4$ & $1-2$ & Blood serum & $\leq 1 \mathrm{~h}$ & {$[35,36]$} \\
\hline
\end{tabular}

to about $240 \mathrm{ng} / \mathrm{ml}(100 \mathrm{IU} / \mathrm{ml})$, remains relatively constant until about the age of 60 and, then, slowly decreases [22]. Therefore, the person is regarded allergic, if the total concentration of $\mathrm{IgE}$ antibodies in his blood serum is higher than $240 \mathrm{ng} / \mathrm{ml}(100 \mathrm{IU} / \mathrm{ml})$ [23].

However, for a precise and safe diagnosis, as well as constant disease monitoring, the concentration of specific $\operatorname{IgE}$ antibodies, produced against particular allergens, can be measured providing so called component-resolved diagnostics (CRD) of the allergy [37,38]. In this case, diagnostic threshold levels of specific IgE antibodies vary significantly for different allergens [39,40]. CRD is particularly important in the case of food allergies to define the 'culprit' proteins, as many food products are the sources of more than 5 different allergenic molecules [41]. Moreover, it provides the possibility to perform cross-reactivity studies and to constantly monitor the level of specific IgE antibodies against various individual allergens for the prognosis of the allergy outgrowth and tolerance development [42].

\section{ELISA-based immunoassays}

Immunoassays, especially classical sandwich enzyme-linked immunosorbent assay (ELISA), are 
the main techniques used for accessing the level of $\mathrm{IgE}$ antibodies (both total and specific) in the patient organism. Simple commercial ELISA kits or complete automated immunoassay platforms are available from different companies: Abnova (Germany) [18], ImmunoCap (Phadia, ThermoScientific, Sweden) for total and specific IgE quantification [43,44], Immulite (Siemens, Germany) and Hytec-288 (Hycor, USA) [40]. The standard kits typically provide the limit of detection (LOD) for total $\operatorname{IgE}$ quantification around $12 \mathrm{ng} / \mathrm{ml}$ (5 IU/ml) [23], while automated platforms possess the sensitivity at $0.24 \mathrm{ng} / \mathrm{ml}(0.1 \mathrm{IU} / \mathrm{ml})$ level $[43,44]$.

For improved CRD of food allergies, microarray systems of immune solid-phase allergen chips (ISAC) ImmunoCAP (Phadia, ThermoScientific, Sweden) are also commercially available [24]. ISAC ImmunoCAP functioning principle is based on a semi-quantitative nonclassical sandwich ELISA, where the blood serum of the patient, containing specific $\mathrm{IgE}$ antibodies, is added to the polymer slide. This slide contains four microarrays with covalently immobilized antigens (different allergens), that bind the IgE antibodies from the blood serum. Then, the solution of antihuman IgE antibodies labeled with fluorescent marker is added to the microarrays. The presence of the fluorescent marker and, consequently, of allergen-bound specific IgE antibodies is measured by the fluorescence using laser scanner [24].

Despite the semi-quantitative data obtained using fluorescence detection, ISAC ImmunoCAP technique was proven to be reliable, but not recommended as a single source of diagnostic information, particularly in the cases, where it has a major impact on the prescribed therapy [45]. Moreover, all the commercial products described above do not provide equivalent results [40], require between 25 and $40 \mu \mathrm{L}$ of blood serum and 3-4 $\mathrm{h}$ for completing the diagnostic procedure. The reduction of the time and sample consumption for such analysis is needed and, therefore, constantly stimulates the scientific development in this direction.

Under laboratory development, IgE antibodies detection was proposed to be realized using various classical ELISA versions $[46,47]$ or microarray chip with diamond-like carbon solid support for the high density immobilization of the antigen (Figure 2A \& B) [25]. Using a concept similar to the ISAC ImmunoCAP technique (Figure $2 \mathrm{C}-\mathrm{E}$ ), the proposed method requires only $2 \mu \mathrm{l}$ of blood serum for the profiling of allergen-specific $\operatorname{IgE}$ antibodies with the 4-8 times better sensitivity than ISAC system and could be its potential alternative [25].

\section{Other types of immunoassays}

Imaging based on surface plasmon resonance, another traditional immunoassay technique, was recently reported for probing antibodies avidity in the allergy diagnosis [48]. Enhancement of surface plasmon resonance signal by the application of Au nanoparticles was shown to provide ultrasensitive total $\operatorname{IgE}$ quantification with LOD of only $0.18 \mathrm{pg} / \mathrm{ml}(0.075 \mathrm{mIU} / \mathrm{ml})$ [26]. Nanocrystal clusters [27] and nanoparticle hybrid probes-based immunoassays [28,49], electrochemical immunosensors [29,50] and magnetophoretic immunoassays [30] were also developed for the quantification of total or specific IgE antibodies in blood serum of the allergic patient or standard IgE solutions (Table 1).

\section{Aptamer-based assays}

Another important group of techniques for allergy diagnosis is based on the application of aptamers instead of the appropriate antihuman IgE antibodies. Aptamers are artificial oligonucleotides (DNA or RNA) that possess a high binding affinity to a selected target molecule, for example, small organic molecule, peptide or protein [51]. Such oligonucleotides are synthesized from random sequence libraries of nucleic acids by in vitro evolution process, called systematic evolution of ligands by exponential enrichment (SELEX), and display in contrast with antibodies high chemical stability, ensured high selectivity and target flexibility [52]. Therefore, aptamers are often used as a replacement for antibodies in the affinity-based assays, including the methods of allergy diagnosis like, for example, aptamer-barcode enhanced chemiluminescence immunosensor [31], aptamer affinity probe capillary electrophoresis [32], electrochemical aptasensor [33] and immuno-polymerase chain reaction (ImmunoPCR) [53].

For the immuno- and aptamer-based methods listed above, LOD values vary between $5 \mathrm{pg} / \mathrm{ml}$ $(0.002 \mathrm{IU} / \mathrm{ml})$ and $2.4 \mathrm{ng} / \mathrm{ml}(1 \mathrm{IU} / \mathrm{ml})$, while the sample volumes applied are in the range of $10-100 \mu \mathrm{l}$ (Table 1). Typically the low sample consumption is more significant for allergy diagnostic tests than extremely high sensitivity. It is especially crucial for the infants, as in their case the available amount of the blood sample is often restricted. Moreover, a small amount of the sample needed means in general less invasive and painful procedure of the blood sampling for the allergic patient. It is quite important taking into account that $\operatorname{IgE}$ antibodies-related measurements are performed multiple times during the patient life for monitoring the disease evolution, controlling the effectiveness of the proposed antiallergic therapy and outgrowth prediction [39].

\section{Fast lateral flow assay}

Another significant feature for any diagnostic procedure is the time of the analysis. The quickest allergy CRD was recently proposed using a lateral flow paper microarray with colorimetric detection, enhanced by the application of gold nanoparticles labeled both with antihuman 
(A)

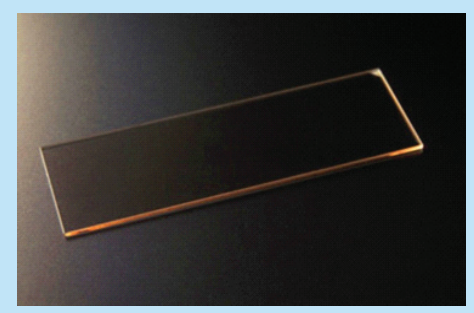

(C)

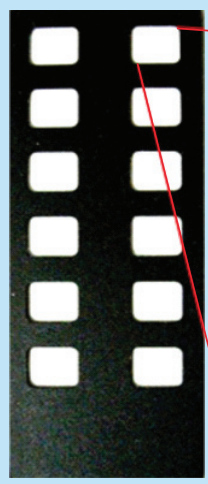

(B)
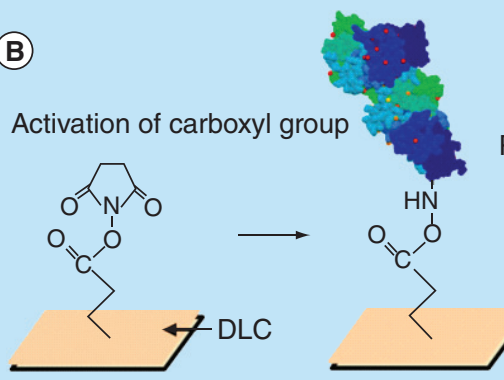

Protein immobilization

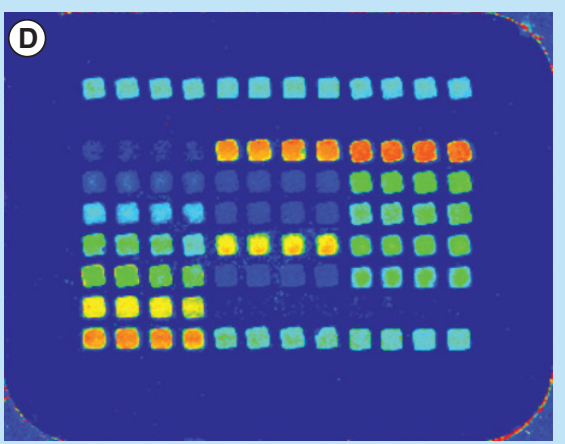

(E)

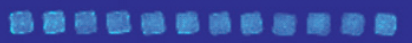

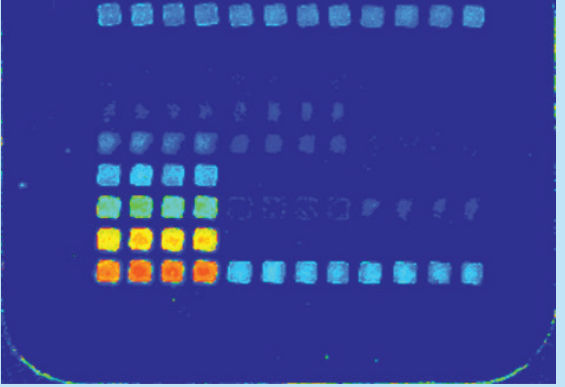

Fluorescence Intensity

Low High

Figure 2. Microarray chip with diamond-like carbon solid support. (A) The DLC slide; (B) antigen immobilization processes on the DLC chip; (C) general layout of the allergens on the DLC chip; (D) profiling specific IgE antibodies from the serum of a patient with egg white and milk allergy and (E) from a nonallergic individual (control). Dp: Dermatophagoides pteronyssinus; GD: Guideline dot by IgE standard. Reproduced with permission from [25] @ Elsevier (2011).

$\mathrm{IgE}$ antibodies and horseradish peroxidase [34]. The whole procedure, schematically illustrated in Figure 3, takes less than $10 \mathrm{~min}$ to complete, requires $30 \mu \mathrm{l}$ of patient blood serum and implements a consumer-grade flatbed scanner or a smartphone as a detection system. Such technique provides only semi-quantitative results, but due to its low cost, portability and short experimental time, it can be a helpful tool for allergy screening in the conditions, where cost-efficiency and ease of use are of the primary importance.

\section{IACE-based assays}

To efficiently perform a general allergy diagnosis in a quantitative manner within less than $50 \mathrm{~min}$, immunoaffinity capillary electrophoresis (IACE) with laser-induced fluorescence (LIF) detection was proposed by our laboratory [35]. As a hybrid technique combining the immunoaffinity extraction of the sample with its electrophoretic separation, IACE is a powerful tool for the analysis of the complex biological samples [54]. For the total IgE quantification by IACE-LIF, magnetic beads, coated with antihuman IgE antibodies, were first trapped inside the separation capillary using two permanents magnets. After the injection of diluted blood serum and $\operatorname{IgE}$ antibodies binding to the magnetic beads, secondary antihuman $\operatorname{IgE}$ antibodies, labeled with a fluorescence marker, were introduced into the capillary. Once the sandwich immunocomplex was formed, it was eluted from the magnetic beads by the acid buffer and stacked by transient isotachophoresis, 


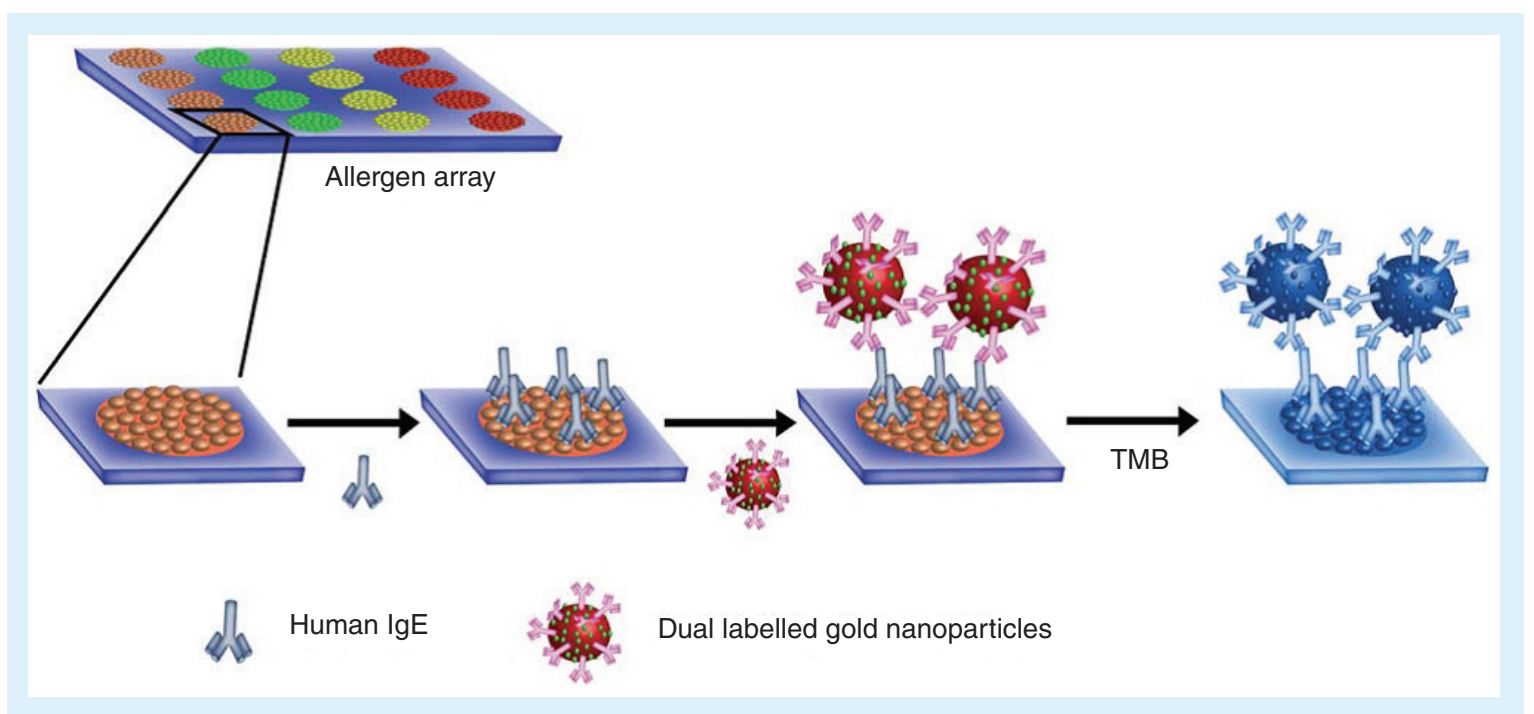

Figure 3. Paper-based lateral flow allergen microarrays. The blood serum of allergic patient flows through a nitrocellulose membrane with the spots of different allergens leading to the binding of IgE antibodies to specific allergen spots. After washing, exposer with dual labeled gold nanoparticles and substrate addition, the colored spots are ready for the analysis with a scanner.

Reproduced with permission from [34] @ The Royal Society of Chemistry (2014).

followed by electrophoretic separation with LIF detection. Such diagnostic procedure required only $1 \mu \mathrm{l}$ of patient blood serum to obtain the LOD of $2.4 \mathrm{ng} / \mathrm{ml}$ (1 IU/ml) with relative standard deviation of $10 \%[35]$.

As CRD can bring more relevant information than just general allergy diagnosis, magnetic beads-based IACE with UV and matrix-assisted laser desorption/ ionization-MS (MALDI-MS) detection was recently developed by our laboratory for the CRD of cow's milk allergy [36]. Following the workflow shown in Figure 4, this technique allowed not only total $\operatorname{IgE}$ quantification, but also the direct identification of the milk sensitizers for the chosen patient using only $2 \mu \mathrm{l}$ of his blood serum.

As a first step (Figure 4A), the $\operatorname{IgE}$ antibodies in the patient blood serum were quantified directly by IACEUV without any labeled sandwich immunocomplex and with the LOD of $0.24 \mathrm{ng} / \mathrm{ml}(0.1 \mathrm{IU} / \mathrm{ml})$. As a second step (Figure 4B), the same IACE protocol for the total IgE quantification was applied for the on-line IgE antibodies extraction on the MBs surface via the formation of antihuman IgE-IgE antibodies immunocomplex directly inside the CE separation capillary. After the stabilization of this complex by chemical cross-linking (Figure 4C), this newly obtained immunosupport was used in the IACE-UV/MALDI-MS analysis of individual milk proteins, as well as milk fractions, in order to perform comprehensive CRD of cow's milk allergy. Obtained results were confirmed by the performance of classical ELISA for specific $\mathrm{IgE}$ antibodies using commercial kits [36].

One of the main advantages of the described CRD procedure is the use of MALDI-MS as a detection method. It allowed the CRD performance not only with individual purified allergens, but also the direct implementation of food extracts. Such approach for allergy diagnosis opens the possibility of the allergen mass/ structure characterization leading to the identification of the allergies to rare (e.g., bovine IgG antibodies in the case of cow's milk allergy [55]) or unknown allergens. It is an important characteristic, as unexpected or rare allergens are normally disregarded by most of the CRD techniques, both commercial and under laboratory development. These diagnostic procedures employ only purified recombinant allergens from a standard list, defined for every type of the food allergy [56]. On the one hand, the application of recombinant allergens removes the necessity of laborious food extract preparation, unifies the experimental workflow and decreases the chances to miss some of the allergenic molecules due to their low expression in a given type of allergen source [57]. But on the other hand, if the patient possesses an allergy to a compound, which is not in the standard list and, therefore, cannot be detected, CRD will provide a false negative result. To avoid such situations of the failure in allergy diagnosis, especially in complicated clinical cases, it is necessary to use the food extracts along with the recombinant allergens, as was already proposed for the CRD of the allergy to kiwifruit [48]. Meanwhile, the application of MS-based techniques, like described IACE-UV/MALDI-MS analysis, will help to reveal the mass and the structure of the new allergens within such diagnostic procedures. Another possibility is to constantly update the diagnostic list of allergens with the newly discovered sensitizers. However, it requires 


\section{Blood serum}

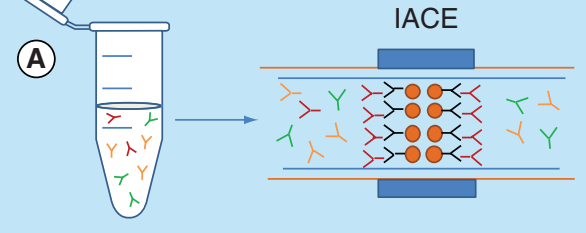

$[$ Total lgE] $(\mathrm{ng} / \mathrm{ml})$
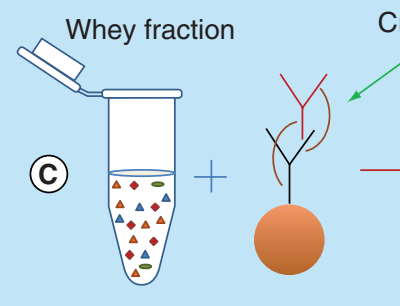

Crosslinking

(B)

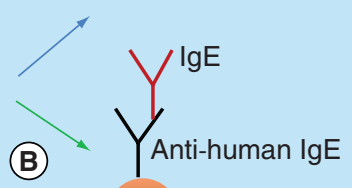

IACE
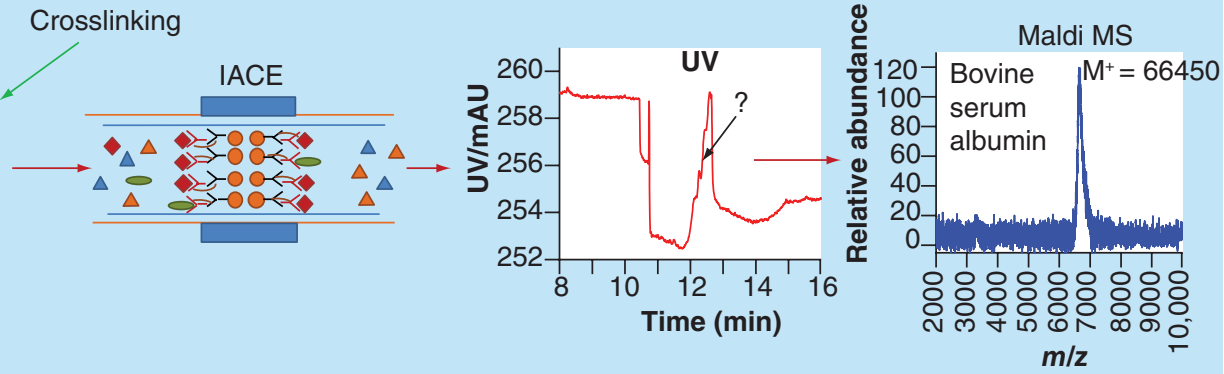

Figure 4. The general experimental workflow for the allergy component-resolved diagnostics by IACE-UV/MALDI-MS analysis.

(A) Total IgE quantification in the blood serum of the milk allergic patient by IACE-UV analysis; (B) IgE antibodies extraction using IACE protocol and further IgE antibodies fixation on magnetic beads surface by cross-linking reaction; (C) CRD of cow's milk allergy by IACE analysis with UV and MALDI-MS detection using magnetic beads with cross-linked immunocomplex.

IACE: Immunoaffinity capillary electrophoresis.

Reproduced with permission from [36] @) American Chemical Society (2014).

the production of these new allergens in a recombinant form for further application in CRD.

\section{Allergen detection}

Despite the optimistic results of many clinical trials involving various types of immunotherapy against various allergies, there is still a lot of work to be done for obtaining a well-established, effective and long-termed allergy cure [59]. Early recognition, symptomatic treatment and avoidance of allergen sources are currently the main standard measures to be taken against allergies $[2,60]$. To simplify the avoidance of offending allergens, many food manufacturers fabricate nowadays hypoallergenic products containing either no allergen at all, like gluten- or diary-free foodstuffs, or containing processed allergens. Food processing for reducing its allergenicity can be performed via heat or high pressure treatment, enzymatic hydrolysis and glycation reactions [61]. Hypoallergenic formulas based on hydrolyzed milk proteins for infants with cow's milk allergy are commercially available since 1985 . Recent laboratory studies have shown potential hypoallergenicity of peanut-polyphenol edible matrix [62] and cashew allergens treated with sodium sulfite in a temperature-dependent manner [63].

However, allergen avoidance, particularly in case of food allergies and commercially prepared food, is difficult to be completely accomplished: $40-100 \%$ of deaths due to food anaphylaxis arise from the consumption of meals, which were prepared away from home [60]. Therefore, a strict control of the allergen content in alimentary products and proper labeling should be constantly provided together with respective legal regulation [64]. Especially, it concerns industrial food products with unexpected allergen cross-contamination, for instance, by wash waters in vegetable processing industry [65]. Or it can be a planned allergen addition, which is not obvious for the consumers, like the supplementation of milk and egg proteins as fining reagents in white wines [66,67] and lysozyme as a microbial stabilizing component for all types of wine [68]. To realize a proper food quality control and labeling, efficient and sensitive analytical techniques are required for the detection of known and new allergens in various matrices. Allergen quantification in a sample is also very important as its dose defines the severity of allergic reactions in the affected person [41]. Most commonly used techniques for quantitative allergen detection in various food products are summarized schematically in Figure 5 and discussed in detail below.

\section{Immunoassays}

Immunoassays are one of the most popular methods of the quantitative allergen detection due to their high sensitivity, specificity and versatility $[69,70]$. The typical method of choice is a direct or indirect format of classical sandwich ELISA using either patient blood serum with specific IgE antibodies or particular allergen-specific IgG antibodies [2,69,71-73]. Primary antibodies for the allergen recognition are 


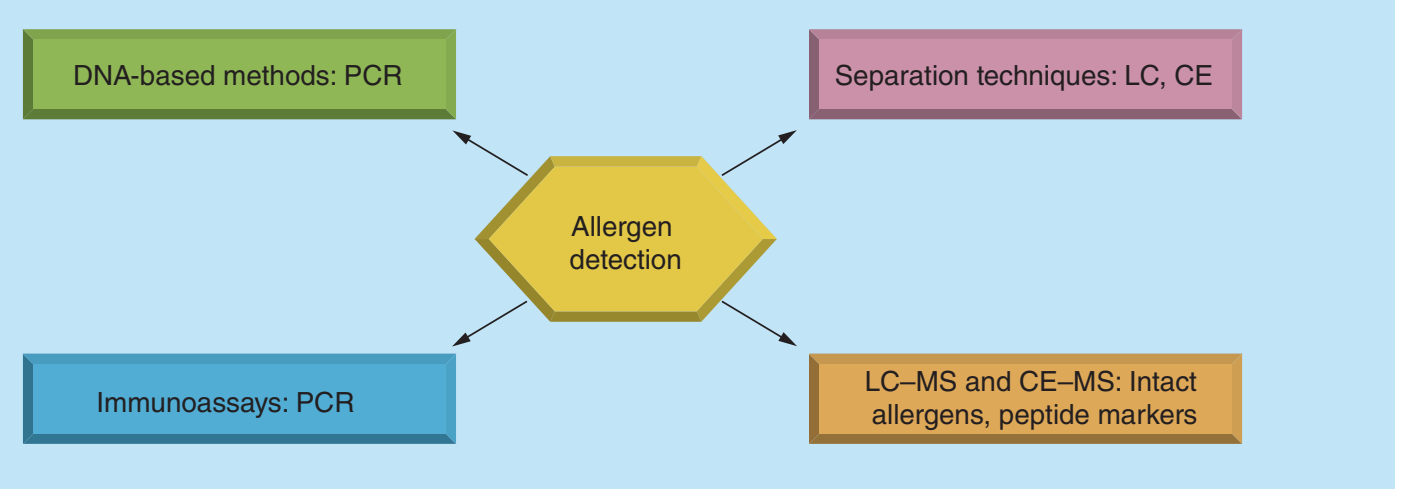

Figure 5. Main analytical techniques used for the allergen detection and quantification in food products.

often specially produced against the allergen extract from the target food product, as it was reported recently for analysis of hazelnut allergens in chocolate [70] and casein detection in white wines [74]. ELISA directly assesses the quantity of the allergen in the sample with a low-cost set-up, within a moderate experimental time and is commercially available as ready-to-use kits for various allergens [72,75-76]. It can be also implemented for the analysis of air samples, contaminated with aerosolized food allergens during food manufacturing, as was demonstrated on the example of tropomyosin detection in crab processing facilities [77]. However, this technique provides a significant rate of false positive results due to antibodies cross-reactivity. It is also prone to false negative results due to conformational changes of allergens and epitope alteration, and, hence, the data obtained by ELISA should be verified by other methods [72,78] .

\section{DNA-based methods}

An attractive alternative to ELISA is the DNA-based methods involving PCR, where cDNA of an allergenic molecule is targeted and amplified by DNApolymerase for further allergen detection and quantitation $[2,69,73]$. As DNA is stable against thermal treatment, hydrolysis and $\mathrm{pH}$ alteration, often occurring during industrial food processing, it is an ideal target for the specific allergen detection with low risk of cross-reactivity phenomena [78]. Moreover, PCRbased experiments are fast, simple to conduct and to integrate into routine analysis [75]. Recent examples of real-time PRC application were reported for the detection of hazelnut [71], pistachios [79], sesame [80], fish [75], almonds [78] and mustard [76] allergens in commercial food products. Meanwhile, microarrays and microchips for cDNA detection [81] are less common than protein-based ones, but commercial PCR kits are also available on the market $[69,75]$. However, despite all the advantages, DNA-based techniques do not detect the allergen molecules themselves and do not access the real allergen concentration in the samples [73]. Therefore, they are not recommended for the proper risk assessment and management [2].

\section{Separation techniques \& MS}

Direct allergen detection and quantification are often realized by separation techniques such as LC [82,83] and CE [84] with UV [85-88] or fluorescence detection $[89,90]$. The utilization of such detectors suffers from false positive results due to the potential coelution of other compounds present in the sample matrix. To avoid this negative effect, separation techniques are typically coupled with MS for unambiguous allergen detection [2,83-84]. In this case, one possibility is to perform the direct MS detection of the allergen molecule itself, as it was realized by ultra-performance LC-MS [91] and IACE-MALDIMS [92] for the quantification of milk whey allergens. Another approach, which is typically applied for LC-MS/MS, is based on the detection of target characteristic peptides from the allergenic molecule and not the entire allergen (Figure 6) [71].

To choose such target peptides, in other words, allergen markers, preliminary untargeted MS analysis is performed using the allergen protein extract from the target food product [93]. This protein extract is enzymatically digested and analyzed by LC-MS/ MS for the identification of allergen peptide markers. Careful choice of the standard peptides from the obtained data should be based on few considerations: these peptides should be a representative and abundant product of the target allergen digestion and should be stable to various industrial treatment procedures (heating, hydrolysis, etc.) [94]. Once the proper selection of peptide markers is done for every

\section{Key term}

cDNA: Double-stranded complementary DNA synthetized from a messenger RNA template in a reaction catalyzed by the reverse transcriptase. 


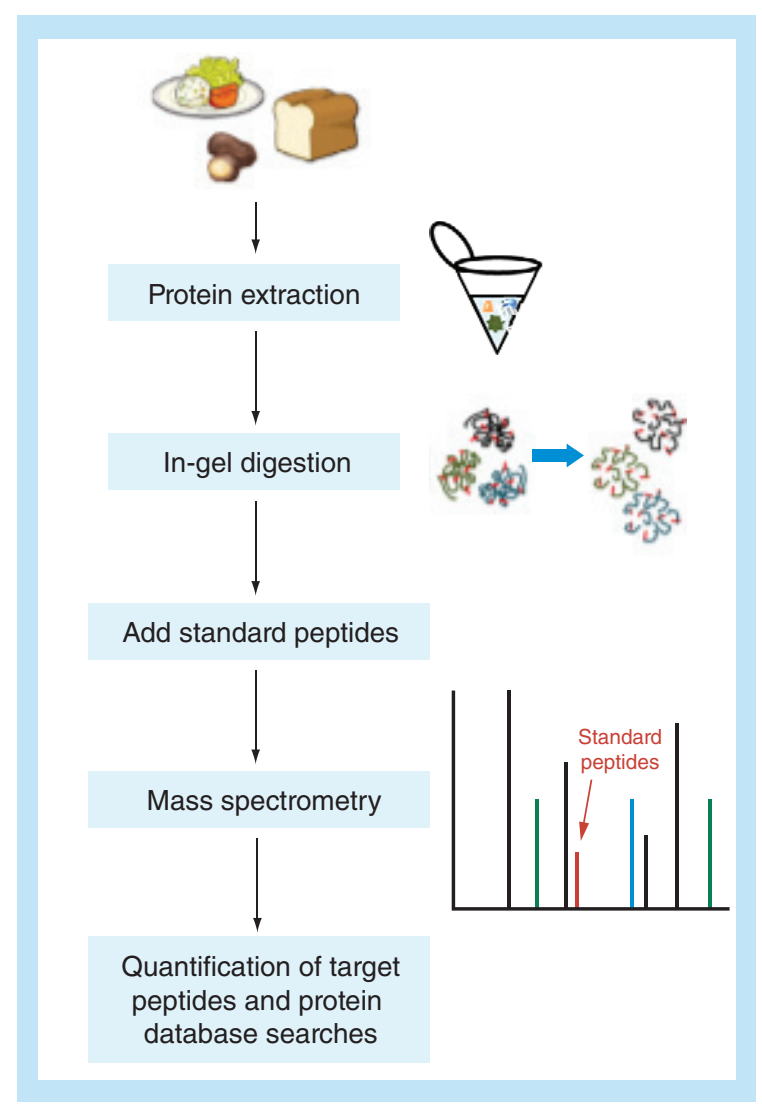

Figure 6. The allergen quantification in food products using allergen peptide markers.

Reproduced with permission from [57] @ Elsevier (2013).

chosen allergen, it is possible to perform the multiallergen quantification in the protein extract from food products of interest. The standard procedure for such analysis is illustrated in Figure $6[66,95]$. Prepared food extract is submitted to a tryptic digestion in bulk solution or in-gel format, which benefits from the additional reduction of the sample complexity due to in-gel electrophoretic separation [96]. Then, the obtained digest is analyzed by LC-MS/MS with selective reaction monitoring or multiple reaction monitoring mode of detection [57,69]. Before the LC-MS/MS run, the standard peptide(s) can be added for further relative quantification, but it is not obligatory, as the quantification can be also done based on the absolute peak intensities of the target peptide markers $[72,93]$. Peptide tagging methods, such as isobaric tagging for relative and absolute quantification and isotopically labeled internal standards are also employed during allergen analysis by LC-MS/MS [73]. The sensitivity reached for various alimentary products is normally in the low ppm range $[69,94,97]$. For instance, LC-MS/MS was recently reported for the quantification of hazelnut allergens in chocolate [71], egg allergens in wine [66] and incurred pasta [72], or egg, soy and milk allergens in cookies [93].

\section{Allergenomics \& new allergen discovery}

Separation techniques with MS detection are attractive not only because of the direct allergen identification and quantification with high sensitivity, accuracy and specificity, but also due to the possibility of the allergen structural characterization and new allergen discovery $[41,69,84,97]$. Exact allergen structure and amino acid sequence are defined by means of bottom-up proteomics [94], called in this case allergenomics [98]. Allergenomic data are crucial for the mapping of epitopes, which positioning in the molecule defines the structure of allergen-based vaccines for the immunotherapy [97,99], the antigens for CRD and allows the cross-reactivity syndrome prediction [7,57]. Moreover, proteomics of processed allergens provides important information about changes in the allergens structure and, consequently, allergenicity upon food processing during either industrial production or cooking at home. Such allergenomic studies were recently presented for the heat processing influence on the allergens in black tiger prawns [100] and peanuts [101].

Standard allergenomic experiment for the allergen discovery/identification and characterization (Figure 7) involves the preparation of the allergen protein extract, its separation by two-dimensional gel electrophoresis (2-DGE) and detection of the IgE antibodies-binding spots on the gel by immunoblotting. Identified spots with allergens are further subjected to in-gel tryptic digestion. Resulted peptides are extracted from the gel and submitted to MS [98,102] or LC-MS/MS [103,104] analysis followed by database search [41,57]. Prior to 2-DGE the allergen extract can be processed by reverse-phase LC [103-105], size-exclusion and hydrophobic interaction chromatography [106], combination of anion-exchange, cationexchange chromatography and reverse-phase LC [94,107]. The discovery and characterization of new allergens were recently reported for rice [108], clementine [109], kiwi [58], Nile perch and cod fish [110].

After the discovery of new putative allergens by allergenomics, it is still necessary to check the level of their allergenicity, as these allergens can bind to patient $\operatorname{IgE}$ antibodies without causing the cross-linking of FceRI receptors on the mast cells, in other words, without mast cell activation and, hence, allergic reaction initiation [57]. Such allergenicity verification and tests for the confirmation of new allergen status can be conducted in vivo by SPT [108] or in vitro by basophil activation test $[100,108]$ and cultured mast cells activation test [111].

Despite all the advantages of MS-based methods for allergen identification and quantification, they are still prone to erroneous results. It happens due to the reduced 
extractability of the analyte from complex matrices, alteration of the allergen biomarker structure during food processing, which results in the mass shift, poor ionization or reduced allergen proteolysis [2]. Another problem, arising from the high detection sensitivity of MS techniques, is a masking of the signals from lowabundant allergens by external contaminants, for example, keratin presented in the skin cells and, hence, on the researcher hands and even exhaled breath [41]. This issue especially concerns the identification of new allergens, which are expected to be low-abundant proteins, as most of the highly-abundant allergenic molecules are already known (350 proteins according to the IUIS Allergen Nomenclature SubCommittee) [94].

Moreover, discovery of new allergens using bottomup proteomic approach is limited by the quality of existing databases and by the potential absence of the considered unknown protein sequence there [41]. In such cases, de novo sequencing of tryptic digest components can be performed, for instance, for new isoforms of fish allergens [112]. This methodology predicts full or partial peptide sequence and strongly depends on the quality of obtained MS/MS results [113]. At the same time, the discrimination between amino acids with identical masses (leucine and isoleucine, lysine and glutamine) remains problematic as well. Amino acid derivatization followed by its MS/MS fragmentation is proposed to overcome this limitation [114].

The described weaknesses of allergenomic strategies for new allergen identification lead to the necessity in the application of DNA-based techniques [115] or in Edman degradation performance for peptide sequencing $[41,58,116,117,118]$. It insures unequivocal identification of amino acid order in the peptide starting from the $\mathrm{N}$-terminal residue and is typically realized in parallel with de novo sequencing [82-84].

Potentially, the dynamic combination of MS, DNAbased methodologies and Edman degradation should be an ideal strategy for the discovery of new allergens. In general, the significant amelioration in this field can be achieved only, when all the steps involved in allergen identification (extraction, separation, detection of IgE-binging components, MS/MS analysis or Edman degradation sequencing, data treatment, allergenicity verification) are constantly improved. So far, there are no allergenic sources with a complete allergen profile [41]. Constant enhancement of the existing technologies and development of the new ones are necessary for shifting the research from already well-characterized abundant allergens to the still unknown low-abundant ones. In this case, new efficient extraction procedures [107], techniques for the depletion of high-abundant allergens [119] and allergen proteome mining with combinatorial peptide ligand libraries $[120,121]$ could help to find, characterize

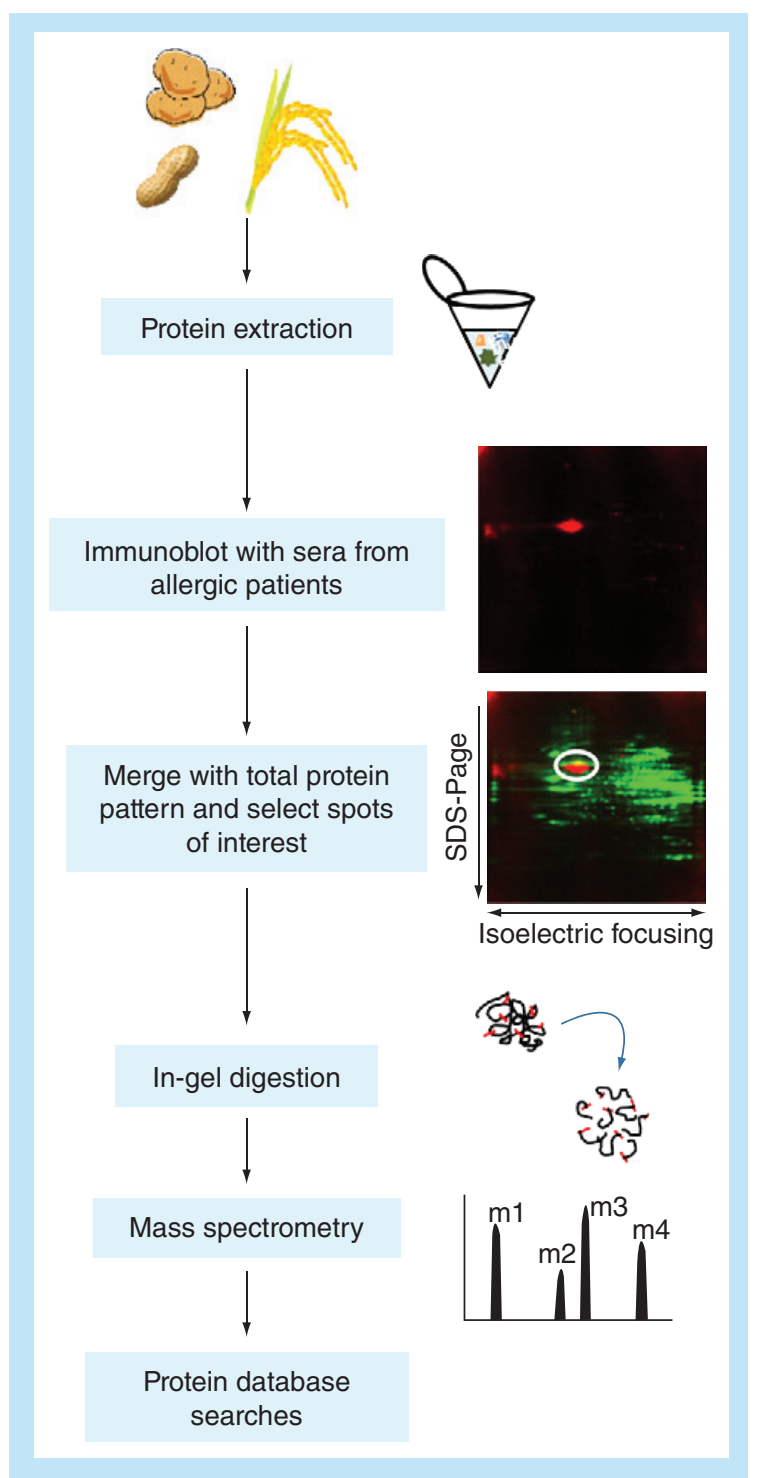

Figure 7. Typical allergenomic procedure for the allergen discovery/identification and characterization. PAGE: Polyacrylamide gel electrophoresis; SDS: Sodium dodecyl sulfate.

Reproduced with permission from [57] () Elsevier (2013).

and integrate into the allergy diagnostics the new allergens with low extractability and/or low abundance in the allergen sources.

\section{Conclusion}

As one of the emerging health problems, especially in pediatrics, allergy requires constant improvement in the speed and quality of its diagnostic tools. Currently, in vivo tests keep being the golden standard for the allergy diagnosis. However, in vitro diagnostic techniques, such as basophil activation tests and various immunoassays, also remain important, as they provide in a safe manner the quantitative information, necessary for the disease 
monitoring and allergy resolution prediction. The correct implementation of these results to the clinical practice allows the planning of allergy treatment, which nowadays is mainly based on the immunotherapy using recombinant allergens.

Meanwhile, as the main precaution measure the allergic persons should avoid the allergen sources and consume preferably hypoallergenic food products. For this purpose, the food manufacturers should constantly provide strict allergen content control in alimentary products and proper foodstuff labeling. ELISA, real-time PCR and LC-MS/MS are currently the methods of choice for precise and sensitive allergen detection in the food products. MS-based techniques for allergen proteomics also reveal the crucial information about allergen structure, used for development of CRD and immunotherapeutic vaccines, cross-reactivity syndrome studies, recombinant allergen production. Moreover, together with the chemical peptide sequencing by the Edman degradation, allergenomic methods are nowadays the only effective tools for the discovery and characterization of new allergens.

\section{Future perspective}

All allergy-related scientific fields are evolving very fast in order to solve the main issues associated with this disease. The common efforts of medical doctors and scientists already have provided a significant success in the field of allergy treatment and have brought the immunotherapy to a new level of efficiency with good quality vaccines. The improvement in the interpretation of in vitro diagnostic results, obtained by CRD, will also significantly help with the correct development of efficient allergy treatment. The technical progress of CRD itself as a diagnostic procedure, will be related with closer interaction or even integration of MS techniques with diagnostic methodologies for detection purposes. The authors believe that in future allergenomic techniques will transform into the effective approach for personalized allergy diagnosis and individual allergen profiling, also remaining the main instrument for new allergen discovery. Meanwhile, the advancement in this domain, as well as in the field of sensitive allergen detection for food quality control, will strongly depend on the sample pretreatment approaches, aimed to extract and purify trace amount of allergens prior to their identification, characterization and quantification.

\section{Financial \& competing interests disclosure}

The authors have no relevant affiliations or financial involvement with any organization or entity with a financial interest in or financial conflict with the subject matter or materials discussed in the manuscript. This includes employment, consultancies, honoraria, stock ownership or options, expert testimony, grants or patents received or pending, or royalties.

No writing assistance was utilized in the production of this manuscript.

Executive summary

Allergy \& allergens: general information

- Allergy in general and food allergies in particular constantly remain an emerging health problem requiring efficient bioanalytical tools for their diagnosis, treatment development and prevention.

Allergy diagnosis

- Both in vivo and in vitro analytical procedures including MS-based techniques are required for comprehensive allergy diagnosis, disease evaluation monitoring and treatment prescription.

Allergen detection

- The permanent technical improvement in the sensitivity and experimental speed of the allergen detection methods is very important for the successful control of allergen content in various food products aiming proper foodstuff labeling and assurance of consumer's safety.

\section{Allergenomics \& new allergen discovery}

- Various allergenomic techniques are currently the most popular methods for new allergen discovery and characterization, however, requiring the development of more efficient sample preparation procedures and results verification by peptide chemical sequencing.

\section{References}

Papers of special note have been highlighted as:

- of interest; $\bullet$ of considerable interest

1 Janeway CA Jr, Travers P, Walport M, Shlomchik M. Immunobiology: the immune system in health and disease 5 th ed. Garland Science, New York, USA (2001).

- Comprehensive overview of general immunology including allergy and allergy-related biochemistry.
2 Cucu T, Jacxsens L, De Meulenaer B. Analysis to support allergen risk management: which way to go? J. Agric. Food Chem. 61(24), 5624-5633 (2013).

- Critical and comprehensive review about allergen detection methods, problems related with new allergen discovery and ways of allergen risk management.

3 Ispano M, Scibilia J, Ansaloni R et al. Definition and classification of food allergy and intolerance. Rev. Fr. Allergol. Immunol. Clin. 38(Suppl. 1), 179-182 (1998). 
$4 \quad$ Mackay IR, Rosen FS. Allergy and allergic diseases. N. Engl. J. Med. 344(1), 30-37 (2001).

5 Valenta R. The future of antigen-specific immunotherapy of allergy. Nat. Rev. Immunol. 2(6) 446-453 (2002).

6 Kumar S, Verma AK, Das M et al. Molecular mechanisms of IgE mediated food allergy. Int. Immunopharmacol. 13(4), 432-439 (2012).

7 García BE, Lizaso MT. Cross-reactivity syndromes in food allergy. J. Investig. Allergol. Clin. Immunol. 21(3), 162-170 (2011).

8 Morales M, López-Matas MÁ, Moya R et al. Cross-reactivity among non-specific lipid-transfer proteins from food and pollen allergenic sources. Food Chem. 165, 397-402 (2014).

9 Strachan DP. Family size, infection and atopy: the first decade of the 'hygiene hypothesis. Thorax, 55(Suppl. 1), 2-10 (2000).

10 Ahern PP, Faith JJ, Gordon JI. Mining the human gut microbiota for effector strains that shape the immune system. Immunity 40(6), 815-823 (2014).

11 Dorrestein PC, Mazmanian SK, Knight R. Finding the missing links among metabolites, microbes, and the host. Immunity 40(6), 824-832, (2014).

12 Thorburn AN, Macia L, Mackay CR. Diet, metabolites, and 'Western-Lifestyle' inflammatory diseases. Immunity 40 (6), 833-842 (2014).

13 Ballmer-Weber BK. Value of allergy tests for the diagnosis of food allergy. Dig. Dis. 32(1-2), 84-88 (2014).

14 Fiocchi A, Schünemann HJ, Brozek J et al. Diagnosis and rationale for action against cow's milk allergy (DRACMA): a summary report. J. Allergy Clin. Immunol. 126(6), 1119-1128, e12 (2010).

15 Peters RL, Gurrin LC, Dharmage SC et al. The natural history of IgE-mediated food allergy: can skin prick tests and serum-specific IgE predict the resolution of food allergy? Int. J. Environ. Res. Public Health 10(10), 5039-5061 (2013).

16 Balzer L, Pennino D, Blank S et al. Basophil activation test using recombinant allergens: highly specific diagnostic method complementing routine tests in wasp venom allergy. PLoS ONE 9(10), e108619 (2014).

17 Sanz ML, Gamboa PM, De Weck AL. In Vitro Tests: Basophil Activation Tests. In: Drug Hypersensitivity. PWJ, , Ed., Karger, Basel, Switzerland, 391-402, (2007).

18 Ebo DG, Hagendorens MM, Bridts $\mathrm{CH}$ et al. In vitro allergy diagnosis: should we follow the flow? Clin. Exp. Allergy 34(3), 332-339 (2004).

19 Ebo DG, Hagendorens MM, Bridts $\mathrm{CH}$ et al. In vitro diagnosis of IgE-mediated allergy: breakthroughs in the last decade. Expert Rev. Clin. Immunol. 8(1), 9-11 (2012).

20 ALCPO. Flow CAST® Basophil Activation Test (BAT). www.alpco.com/products/Flow_CAST.aspx

21 Michaud B, Aroulandom J, Baiz N et al. Casein-specific IL-4and IL-13-secreting T cells: a tool to implement diagnosis of cow's milk allergy. Allergy 69(11), 1473-1480 (2014).

22 Papamichael K, Kreuzer M, Guilbault G. Viability of allergy (IgE) detection using an alternative aptamer receptor and electrochemical means. Sensors Actuators B Chem. 121(1), 178-186 (2007).
23 ABNOVA. IgE (Human) ELISA Kit.

www.abnova.com

24 Thermo scientific. ImmunoCAP ISAC - When you need the bigger picture in allergy.

www.phadia.com

25 Suzuki K, Hiyoshi M, Tada $\mathrm{H}$ et al. Allergen diagnosis microarray with high-density immobilization capacity using diamond-like carbon-coated chips for profiling allergenspecific IgE and other immunoglobulins. Anal. Chim. Acta 706(2), 321-327 (2011).

26 Kim S, Lee J, Lee SJ et al. Ultra-sensitive detection of $\operatorname{IgE}$ using biofunctionalized nanoparticle-enhanced SPR. Talanta 81(4-5), 1755-1759 (2010).

27 Yao J, Han X, Zeng S et al. Detection of femtomolar proteins by nonfluorescent $\mathrm{ZnS}$ nanocrystal clusters. Anal. Chem. 84(3), 1645-1652 (2012).

28 Li H, Qiang W, Vuki M et al. Fluorescence enhancement of silver nanoparticle hybrid probes and ultrasensitive detection of IgE. Anal. Chem. 83(23), 8945-8952 (2011).

29 De Stefano A, Volpe G, Adornetto G et al. Development of a very sensitive ELIME assay for detection of sIgE to G5 and D2 aeroallergens in serum samples. Electroanalysis 26(6), 1382-1389 (2014).

30 Hahn YK, Jin Z, Kang JH et al. Magnetophoretic immunoassay of allergen-specific IgE in an enhanced magnetic field gradient. Anal. Chem. 79(6), 2214-2220 (2007).

31 Peng Q, Cao Z, Lau C et al. Aptamer-barcode based immunoassay for the instantaneous derivatization chemiluminescence detection of $\operatorname{IgE}$ coupled to magnetic beads. Analyst 136(1), 140-147 (2011).

32 Cheow LF, Han J. Continuous signal enhancement for sensitive aptamer affinity probe electrophoresis assay using electrokinetic concentration. Anal. Chem. 83(18), 7086-7093 (2011).

33 Salimi A, Khezrian S, Hallaj R et al. Highly sensitive electrochemical aptasensor for immunoglobulin $\mathrm{E}$ detection based on sandwich assay using enzyme-linked aptamer. Anal. Biochem. 466, 89-97 (2014).

34 Chinnasamy T, Segerink LI, Nystrand M et al. A lateral flow paper microarray for rapid allergy point of care diagnostics. Analyst 139(10), 2348-2354 (2014).

35 Chen H-X, Busnel J-M, Peltre G et al. Magnetic beads based immunoaffinity capillary electrophoresis of total serum $\operatorname{IgE}$ with laser-induced fluorescence detection. Anal. Chem. 80(24), 9583-9588 (2008).

36 Gasilova N, Girault HH. Component-resolved diagnostic of cow's milk allergy by immunoaffinity capillary electrophoresis - matrix-assisted laser desorption/ionization mass spectrometry. Anal. Chem. 86, 6337-6345 (2014).

- An original paper describing CRD using IACE with UV and MALDI-MS detection.

37 Kim JS, Nowak-W grzyn A. Component-resolved diagnostics: shedding light on the so-called 'squishy science' of food allergies? Int. Arch. Allergy Immunol. 156(3), 231-233 (2011).

38 Hochwallner H, Schulmeister U, Swoboda I et al. Microarray and allergenic activity assessment of milk allergens. Clin. Exp. Allergy 40 (12), 1809-1818 (2010). 
39 Sicherer SH, Sampson HA. Food allergy: Epidemiology, pathogenesis, diagnosis, and treatment. J. Allergy Clin. Immunol. 133(2), 291-307 (2014).

- A recent critical review about food allergy epidemiology, ways of diagnosis and treatment.

40 Goikoetxea MJ, Sanz ML, García BE et al. Recommendations for the use of in vitro methods to detect specific immunoglobulin E: are they comparable? J. Investig. Allergol. Clin. Immunol. 23(7), 448-454 (2013).

41 Ciardiello MA, Tamburrini M, Liso M et al. Food allergen profiling: A big challenge. Food Res. Int. 54(1), 1033-1041 (2013).

42 Ahrens B, Lopes de Oliveira LC, Grabenhenrich L et al. Individual cow's milk allergens as prognostic markers for tolerance development? Clin. Exp. Allergy 42(11), 16301637 (2012)

43 Thermo scientific. ImmunoCAP Tryptase. www.phadia.com

44 Thermo scientific. ImmunoCAP Total IgE. www.phadia.com

45 Martínez-Aranguren R, Lizaso MT, Goikoetxea MJ et al. Is the determination of specific $\operatorname{IgE}$ against components using ISAC 112 a reproducible technique? PLoS ONE 9(2), e88394 (2014).

46 Kreuzer MP, Sullivan CKO, Pravda M et al. Development of an immunosensor for the determination of allergy antibody (IgE) in blood samples. Anal. Chim. Acta 442, 45-53 (2001).

47 Ohashi T, Mawatari K, Sato K et al. A micro-ELISA system for the rapid and sensitive measurement of total and specific immunoglobulin E and clinical application to allergy diagnosis. Lab. Chip. 9(7), 991-995 (2009).

48 Chardin H, Mercier K, Frydman C et al. Surface plasmon resonance imaging: a method to measure the affinity of the antibodies in allergy diagnosis. J. Immunol. Methods 405, 23-28 (2014).

49 Wang J, Munir A, Li Z et al. Aptamer-Au NPs conjugatesaccumulated methylene blue for the sensitive electrochemical immunoassay of protein. Talanta 81(1-2), 63-67 (2010).

50 Lee C-Y, Wu K-Y, Su H-L et al. Sensitive label-free electrochemical analysis of human IgE using an aptasensor with cDNA amplification. Biosens. Bioelectron. 39(1), 133-138 (2013).

51 Willner I, Zayats M. Electronic aptamer-based sensors. Angew. Chem. Int. Ed. Engl. 46(34), 6408-6418 (2007).

52 Song S, Wang L, Li J et al. Aptamer-based biosensors. TrAC Trends Anal. Chem. 27(2), 108-117 (2008).

53 Johnston EB, Kamath SD, Lopata AL et al. Tus-Terlock immuno-PCR assays for the sensitive detection of tropomyosin-specific IgE antibodies. Bioanalysis 6(4), 465-476 (2014)

54 Guzman NA, Blanc T, Phillips TM. Immunoaffinity capillary electrophoresis as a powerful strategy for the quantification of low-abundance biomarkers, drugs, and metabolites in biological matrices. Electrophoresis 29(16), 3259-3278 (2008).
55 Natale M, Bisson C, Monti G et al. Cow's milk allergens identification by two-dimensional immunoblotting and mass spectrometry. Mol. Nutr. Food Res. 48(5), 363-369 (2004).

56 Thermo scientific. ImmunoCAP Allergens. www.phadia.com

57 Nakamura R, Teshima R. Proteomics-based allergen analysis in plants. J. Proteomics 93, 40-49 (2013).

58 Sirvent S, Cantó B, Cuesta-Herranz J et al. Act d 12 and Act d 13: two novel, masked, relevant allergens in kiwifruit seeds. J. Allergy Clin. Immunol. 133(6), 1765-1767, e4 (2014).

59 Casale TB, Stokes JR. Immunotherapy: what lies beyond. J. Allergy Clin. Immunol. 133(3), 612-619 (2014).

60 Pajno GB, Cox L, Caminiti L et al. Oral immunotherapy for treatment of immunoglobulin E-mediated food allergy: the transition to clinical practice. Pediatr. Allergy. Immunol. Pulmonol. 27(2), 42-50 (2014).

$61 \mathrm{Bu} \mathrm{G}$, Luo Y, Chen F et al. Milk processing as a tool to reduce cow's milk allergenicity: a mini-review. Dairy Sci. Technol. 93(3), 211-223 (2013).

62 Plundrich NJ, Kulis M, White BL et al. Novel strategy to create hypoallergenic peanut protein-polyphenol edible matrices for oral immunotherapy. J. Agric. Food Chem. 62, 7010-7021 (2014).

63 Mattison CP, Desormeaux WA, Wasserman RL et al. Decreased immunoglobulin E ( $\operatorname{IgE}$ ) binding to cashew allergens following sodium sulfite treatment and heating. J. Agric. Food Chem. 62, 6746-6755 (2014).

64 Gendel SM. The regulatory challenge of food allergens. J. Agric. Food Chem. 61(24), 5634-5637 (2013).

65 Salomonsson H, Jacxsens L, Perseyn J et al. Risk profiling of wash waters in vegetable processing industry towards possible allergen carry-over. Food Res. Int. 55, 190-196 (2014).

66 Monaci L, Losito I, De Angelis E et al. Multi-allergen quantification of fining-related egg and milk proteins in white wines by high-resolution mass spectrometry. Rapid Commun. Mass Spectrom. 27(17), 2009-2018 (2013).

67 Monaci L, Losito I, Palmisano F et al. Identification of allergenic milk proteins markers in fined white wines by capillary liquid chromatography-electrospray ionizationtandem mass spectrometry. J. Chromatogr. A 1217(26), 4300-4305 (2010).

68 Carstens C, Deckwart M, Webber-Witt M et al. Evaluation of the efficiency of enological procedures on lysozyme depletion in wine by an indirect ELISA method. J. Agric Food Chem. 62(25), 6247-6253 (2014).

69 Costa J, Carrapatoso I, Oliveira MBPP et al. Walnut allergens: molecular characterization, detection and clinical relevance. Clin. Exp. Allergy 44(3), 319-341 (2014).

70 Costa J, Ansari P, Mafra I et al. Development of a sandwich ELISA-type system for the detection and quantification of hazelnut in model chocolates. Food Chem. 173, 257-265 (2015).

71 Costa J, Ansari P, Mafra I et al. Assessing hazelnut allergens by protein- and DNA-based approaches: LC-MS/MS, ELISA and real-time PCR. Anal. Bioanal. Chem. 406(11), 2581-2590 (2014). 
-. A comprehensive illustration of application of three main allergen detection techniques on the example of hazelnut allergens.

72 Azarnia S, Boye JI, Mongeon V et al. Detection of ovalbumin in egg white, whole egg and incurred pasta using LC-ESIMS/MS and ELISA. Food Res. Int. 52(2), 526-534 (2013).

73 Kirsch S, Fourdrilis S, Dobson R et al. Quantitative methods for food allergens: a review. Anal. Bioanal. Chem. 395(1), 57-67 (2009).

74 Deckwart M, Carstens C, Webber-Witt M et al. Development of a sensitive ELISA for the detection of caseincontaining fining agents in red and white wines. J. Agric. Food Chem. 62, 6803-6812 (2014).

75 Herrero B, Vieites JM, Espiñeira M. Development of an in-house fast real-time PCR method for detection of fish allergen in foods and comparison with a commercial kit. Food Chem. 151, 415-420 (2014).

76 Palle-Reisch M, Hochegger R, Štumr S et al. Validation and comparison of two commercial ELISA kits and three in-house developed real-time PCR assays for the detection of potentially allergenic mustard in food. Food Chem. 174, 75-81 (2015).

77 Kamath SD, Thomassen MR, Saptarshi SR et al. Molecular and immunological approaches in quantifying the air-borne food allergen tropomyosin in crab processing facilities. Int. J. Hyg. Environ. Health 217(7), 740-750 (2014).

78 Prieto N, Iniesto E, Burbano C et al. Detection of almond allergen coding sequences in processed foods by real time PCR. J. Agric. Food Chem. 62, 5617-5624 (2014).

79 López-Calleja IM, de la Cruz S, González I et al. Survey of undeclared allergenic pistachio (Pistacia vera) in commercial foods by hydrolysis probe real-time PCR. Food Control 39, 49-55 (2014).

80 Luber F, Demmel A, Herbert D et al. Comparative assessment of DNA-based approaches for the quantification of food allergens. Food Chem. 160, 104-111 (2014).

81 Wang W, Li Y, Zhao F et al. Optical thin-film biochips for multiplex detection of eight allergens in food. Food Res. Int. 44(10), 3229-3234 (2011).

82 Saz JM, Marina ML. High performance liquid chromatography and capillary electrophoresis in the analysis of soybean proteins and peptides in foodstuffs. J. Sep. Sci. 30(4), 431-451 (2007).

83 Fanali C, Dugo L, Dugo P et al. Capillary-liquid chromatography (CLC) and nano-LC in food analysis. TrAC Trends Anal. Chem. 52, 226-238 (2013).

84 García-Cañas V, Simó C, Castro-Puyana M et al. Recent advances in the application of capillary electromigration methods for food analysis and Foodomics. Electrophoresis 35(1), 147-169 (2014).

85 Chen H-X, Busnel J-M, Gassner A-L et al. Capillary electrophoresis immunoassay using magnetic beads. Electrophoresis 29(16), 3414-3421 (2008).

86 Bowker BC, Fahrenholz TM, Sarnoski PJ et al. Alterations in the sarcoplasmic protein fraction of beef muscle with postmortem aging and hydrodynamic pressure processing. J. Food Sci. 77(6), C594-602 (2012).
87 Dullnig V, Weiss R, Amon S et al. Confirmation of immunoreactivity of the recombinant major birch pollen allergen Bet vla by affinity-CIEF. Electrophoresis 30(13), 2337-46, 2009.

88 Ding X, Yang Y, Zhao $S$ et al. Analysis of $\alpha$-lactalbumin, $\beta$-lactoglobulin A and B in whey protein powder, colostrum, raw milk, and infant formula by CE and LC. Dairy Sci. Technol. 91(2), 213-225 (2011).

89 Zienkiewicz A, Zienkiewicz K, Florido F et al. Chip-based capillary electrophoresis profiling of olive pollen extracts used for allergy diagnosis and immunotherapy. Electrophoresis $1-13$ (2014).

90 Garrido-Medina R, Puerta A, Pelaez-Lorenzo C et al. Capillary Electrophoresis With Laser-Induced Fluorescence Detection Of Proteins From Two Types Of Complex Sample Matrices: Food And Biological Fluids. In: Methods in molecular biology. Human Press, USA, 207-225 (2013).

91 Ren Y, Han Z, Chu X et al. Simultaneous determination of bovine alpha-lactalbumin and beta-lactoglobulin in infant formulae by ultra-high-performance liquid chromatographymass spectrometry. Anal. Chim. Acta 667(1-2), 96-102 (2010).

92 Gasilova N, Gassner AL, Girault HH. Analysis of major milk whey proteins by immunoaffinity capillary electrophoresis coupled with MALDI-MS. Electrophoresis 33(15), 2390 2398 (2012).

93 Monaci L, Pilolli R, De Angelis E et al. "Multi-allergen detection in food by micro high-performance liquid chromatography coupled to a dual cell linear ion trap mass spectrometry.," J. Chromatogr. A 1358, 136-144 (2014).

94 Monaci L, Visconti A. Mass spectrometry-based proteomics methods for analysis of food allergens. TrAC Trends Anal. Chem. 28(5), 581-591 (2009).

- A comprehencive overview of allergenomic approaches for detection of food allergens and discovery of new allergens.

95 Mattarozzi M, Bignardi C, Elviri L et al. Rapid shotgun proteomic liquid chromatography-electrospray ionizationtandem mass spectrometry-based method for the lupin (Lupinus albus L.) multi-allergen determination in foods. J. Agric. Food Chem. 60 (23), 5841-5846 (2012).

96 De Ceglie C, Calvano CD, Zambonin CG. Determination of hidden hazelnut oil proteins in extra virgin olive oil by cold acetone precipitation followed by in-solution tryptic digestion and MALDI-TOF-MS analysis. J. Agric. Food Chem. 62, 9401-9409 (2014).

97 Sancho AI, Mills ENC. Proteomic approaches for qualitative and quantitative characterisation of food allergens. Regul. Toxicol. Pharmacol. 58(3 Suppl.), 42-46 (2010).

98 Akagawa M, Handoyo T, Ishii T et al. Proteomic analysis of wheat flour allergens. J. Agric. Food Chem. 55(17), 68636870 (2007).

99 Jankovicova B, Rosnerova S, Slovakova M et al. Epitope mapping of allergen ovalbumin using biofunctionalized magnetic beads packed in microfluidic channels. The first step towards epitope-based vaccines. J. Chromatogr. A 1206(1), 64-71 (2008).

100 Kamath SD, Rahman AMA, Voskamp A et al. Effect of heat processing on antibody reactivity to allergen variants 
and fragments of black tiger prawn: a comprehensive allergenomic approach. Mol. Nutr. Food Res. 58(5), 1144-1155 (2014).

101 Hebling CM, Mcfarland MA, Callahan JH et al. Global proteomic screening of protein allergens and advanced glycation endproducts in thermally processed peanuts. J. Agric. Food Chem. 61, 5638-5648 (2013).

102 Krishnan HB, Kim W-S, Jang S et al. All three subunits of soybean beta-conglycinin are potential food allergens. J. Agric. Food Chem. 57(3), 938-943 (2009).

103 dos Santos-Pinto J. Proteomic strategies for sequencing and post-translational modifications assignment of antigen-5, a major allergen from the venom of the social wasp Polybia paulista. J. proteome Res. 13, 855-865 (2014).

104 Maddumage R, Nieuwenhuizen NJ, Bulley SM et al. Diversity and relative levels of actinidin, kiwellin, and thaumatin-like allergens in 15 varieties of kiwifruit (Actinidia). J. Agric. Food Chem. 61(3), 728-739 (2013).

105 Blank S, Bantleon FI, McIntyre M et al. The major royal jelly proteins 8 and 9 (Api m 11) are glycosylated components of Apis mellifera venom with allergenic potential beyond carbohydrate-based reactivity. Clin. Exp. Allergy 42(6), 976-985 (2012).

106 Bollen MA, Garcia A, Cordewener JHG et al. Purification and characterization of natural Bet $\mathrm{v} 1$ from birch pollen and related allergens from carrot and celery. Mol. Nutr. Food Res. 51(12), 1527-1536 (2007).

107 Nikolic J, Mrkic I, Grozdanovic M et al. Protocol for simultaneous isolation of three important banana allergens. J. Chromatogr. B. Analyt. Technol. Biomed. Life Sci. 962, 30-36 (2014).

108 Humlova Z, Halada P, Janatkova I. Identification of rice proteins recognized by the $\operatorname{IgE}$ antibodies of patients with food allergies. J. Agric. Food Chem. 61, 8851-8860 (2013).

109 Serra IA, Bernardo L, Spadafora A et al. The Citrus clementina putative allergens: from proteomic analysis to structural features. J. Agric. Food Chem. 61, 8949-8958 (2013).

110 Tomm JM, Van Do T, Jende C et al. Identification of new potential allergens from nile perch (Lates niloticus) and cod (Gadus morhua). J. Investig. Allergol. Clin. Immunol. 23(3), 159-167 (2013).
111 Nakamura R, Uchida Y, Higuchi M et al. A convenient and sensitive allergy test: $\mathrm{IgE}$ crosslinking-induced luciferase expression in cultured mast cells. Allergy 65(10), 1266-1273 (2010).

112 Carrera M, Can B, Vazquez J et al. Extensive de novo sequencing of new parvalbumin isoforms using a novel combination of bottom-up proteomics, accurate molecular mass measurement by FTICR-MS and Selected MS/MS Ions. J. Proteome Res. 13, 4393-4406 (2010).

113 Chong KF, Leong HW. Tutorial on de novo peptide sequencing using MS/MS mass spectrometry. J. Bioinform. Comput. Biol. 10(6), 1231002 (2012).

114 Cook SL, Collin OL, Jackson GP. Metastable atomactivated dissociation mass spectrometry: leucine/isoleucine differentiation and ring cleavage of proline residues. J. Mass Spectrom. 44(8), 1211-1223 (2009).

115 Bublin M, Pfister M, Radauer C et al. Component-resolved diagnosis of kiwifruit allergy with purified natural and recombinant kiwifruit allergens. J. Allergy Clin. Immunol. 125(3), 687-694 (2010).

116 Tuppo L, Alessandri C, Pomponi D et al. Peamaclein-a new peach allergenic protein: similarities, differences and misleading features compared with Pru p 3. Clin. Exp. Allergy 43(1), 128-140 (2013).

117 D’Avino R, Bernardi ML, Wallner M et al. Kiwifruit Act d 11 is the first member of the ripening-related protein family identified as an allergen. Allergy 66(7), 870-877 (2011).

118 Bernardi ML, Giangrieco I, Camardella L et al. Allergenic lipid transfer proteins from plant-derived foods do not immunologically and clinically behave homogeneously: the kiwifruit LTP as a model. PLoS ONE 6(11), e27856 (2011).

119 Jmeian Y, El Rassi Z. Liquid-phase-based separation systems for depletion, prefractionation and enrichment of proteins in biological fluids for in-depth proteomics analysis. Electrophoresis 30(1), 249-261 (2009).

120 D'Amato A, Bachi A, Fasoli E et al. In-depth exploration of cow's whey proteome via combinatorial peptide ligand libraries research articles. J. Proteome Res. 8(8), 3925-3936 (2009).

121 D'Amato, , Bachi A, Fasoli E et al. In-depth exploration of Hevea brasiliensis latex proteome and "hidden allergens" via combinatorial peptide ligand libraries. J. Proteomics 73(7), 1368-1380 (2010). 